\title{
RE-CONSIDERING A CIZHOU-TYPE JAR IN THE VVAK COLLECTION
}

\section{Introduction}

Within the collection of the VVAK, on long term loan to the Rijksmuseum Amsterdam, is a Cizhou-type (Cizhouyao xi) stoneware jar (AK-MAK-536, fig. 1). This jar has a short tapered neck, a wide mouth, and four small loops between the neck and the shoulder which would originally have been used to secure a lid; from the square shoulder the sides narrow towards the foot. The inner neck and the body are covered with a crackled glaze and slip to around three centimeters above the base. On the surface of the glaze are cloudy patches of slip that turned pink or brownish-beige during firing. The slip has been worn away around the base. One side is decorated with a painting of a galloping horse, shown running through grassland - as suggested by spare brush strokes. The horse is painted in shades of iron brown beneath the glaze. It has a dark brown body, a yellowish-brown mane, and a tail painted with fluid brushstrokes. On the other side, in the same palette, is an as yet unidentified plant (fig. 2). The base of the jar is plain biscuit (fig. 3).

I first encountered this jar in September 2013 during an interview for my job as curator of Chinese art in the Rijksmuseum. I remember that this jar was placed in front of me and I was asked several questions about it. I explained that conventionally this jar would be dated to the 14th century, but that I would disagree, considering it a 16th century work. Its shape was suggestive of vessels that were used in the Japanese tea ceremony, but at the time I was uncertain of its place of origin. I was even suspicious that this jar could have been a Japanese imitation of Chinese stoneware executed in the Momoyama period (1573-1615) or a Korean Choson period (1392-1910) imitation. Later on, during my service in the Rijksmuseum, I discovered the answer and am thus writing this article to set the record straight. This essay first reconsiders the fundamental identification of the jar, which includes its production

Fig. 1

Cizhou-type jar with underglaze brown painted decoration on a cream slip beneath a yellowish glaze, Pengcheng, Hebei province, 16th century, Rijksmuseum Amsterdam, inv.no. AK-MAK-536. VVAK on long-term loan to Rijksmuseum. location and date. Further, I aim to place it back into its social context to be able to discuss its meaning in the history of East Asian art.

\section{The Production Location and Date of the Jar}

As far as I know, there are several similar jars with the same decoration in various European collections. Examples can be found in the Victoria \& Albert Museum and the British Museum (fig. 4) London, and in the Museum for Applied Arts, Vienna. The VVAK jar in Amsterdam is generally recognized as a 14th century Cizhou-type ware from the Yuan Dynasty (1271-1368). ${ }^{1}$ However opinions on this identification differ. Jessica Harrison-Hall dated 


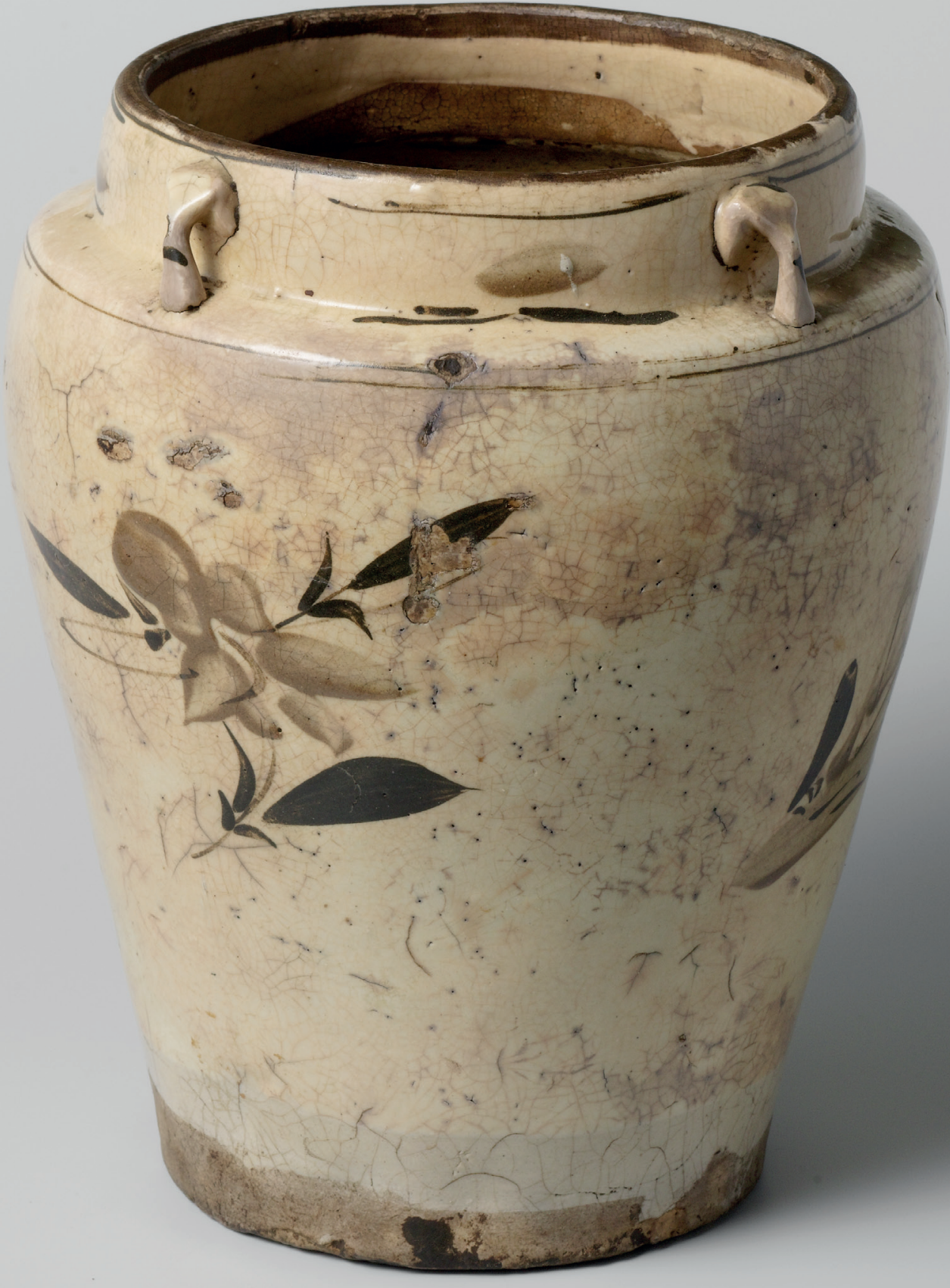


Fig. 2 (left) Jar from figure 1. Photo: Rijksmuseum Amsterdam.

Fig. 3 (right) Jar from figure 1. Photo: Rijksmuseum Amsterdam.

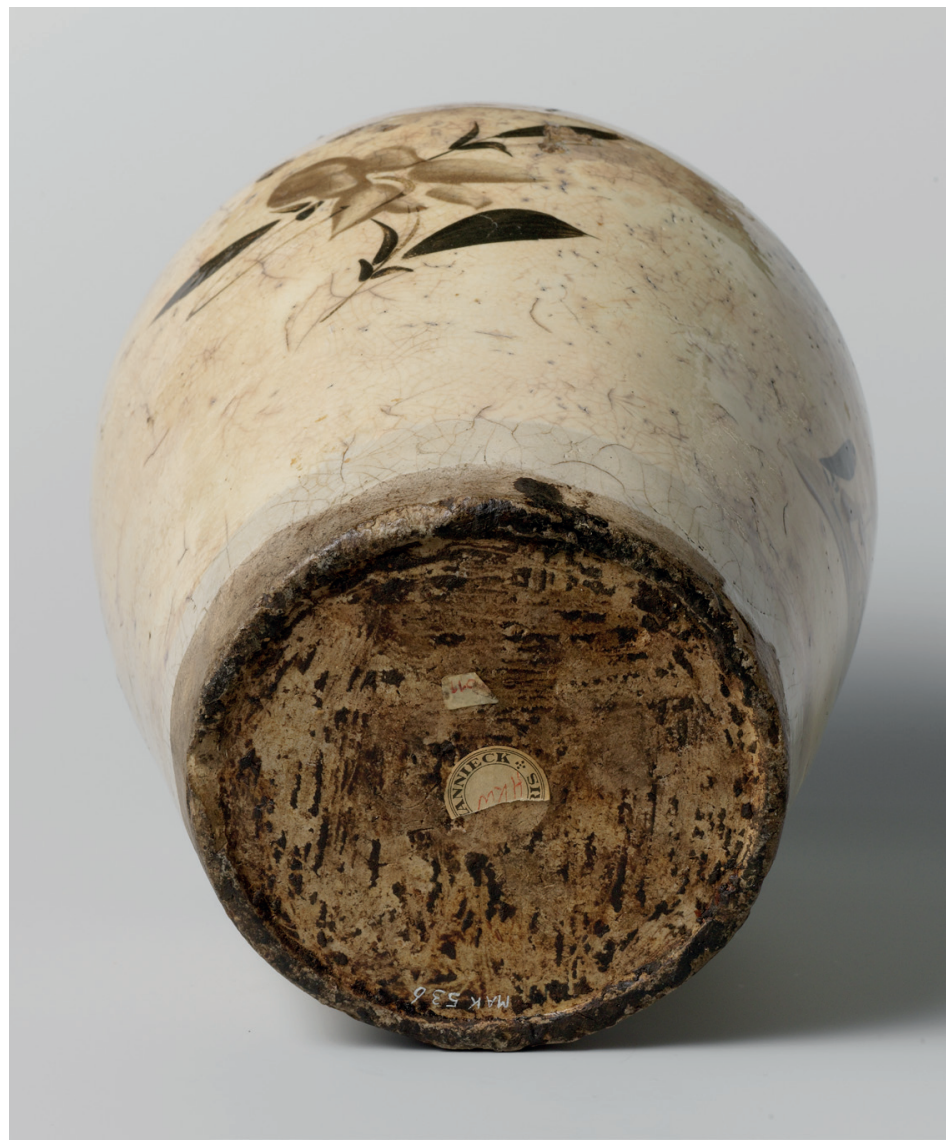

a similar jar in the British Museum to circa 1620-1911 and suggested it was possibly made in Shanxi or Hebei. ${ }^{2}$

Cizhou is, in fact, a term used to classify a wide range of northern Chinese stoneware from Hebei, Henan, Shanxi, Shaanxi, Shandong, and Anhui provinces. The earliest date to the 11 th century (Northern Song), while production continued until the Qing dynasty (1644-1911). The previous identifications and dates are relatively loose and also often incorrect. We are now fortunate that archeological discoveries and research during the last decade enable a more accurate identification of this type of jar. Guo Xuelei's latest research on Ming dynasty Cizhou-type wares classifies them according to different production locations, such as: Pengcheng, Yuzhou, Yaozhou, Huozhou, and Huguan. It is now clear that this type of jar should be dated to the 16 th century and its production location is Pengcheng (modern Handan) in Heibei province. ${ }^{3}$ Thus the identification of the VVAK jar should be: Cizhou-type, Pengcheng-ware, Hebei province, 16th century. According to the 1581 edition of the Gazetteer of Cizhou ('Cizhou zhi'):

Pengcheng, located to the west of Cizhou, belongs to the Fuyuan neighborhood. The people there excel in pottery, [some of which] is decorated with five colours. [They] ship [their products] along the Fu River to the capital. ${ }^{4}$ 

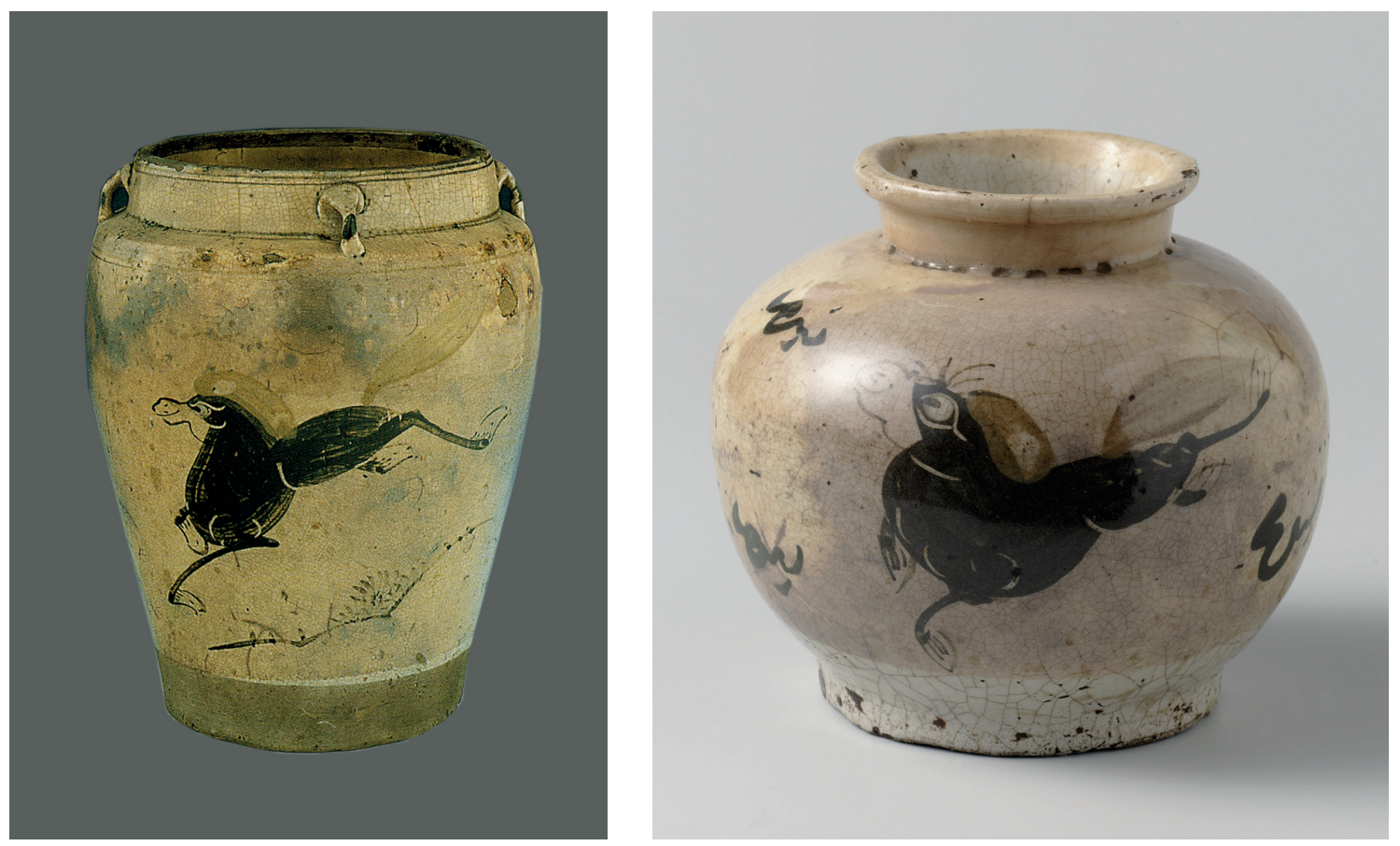

Fig. 4 (left)

Cizhou-type jar with underglaze brown painted decoration on a cream slip beneath a yellowish glaze, Pengcheng, Hebei province, 16th century, British Museum, inv.no. OA 1936.10-12. 41.

Fig. 5 (right)

Cizhou-type jar with underglaze brown painted decoration on a cream slip beneath a yellowish glaze, Pengcheng, Hebei province, 16th century, Rijksmuseum Amsterdam, inv.no. AK-MAK-535. VVAK on long-term loan to Rijksmuseum.
The Gazetteer documents the long tradition of pottery production in this area. In the collection of the VVAK there is another small jar with a different shape but with identical decoration in the same style of brushwork (fig. 5). This jar can also be identified as 16th century Pengcheng-ware (AK-MAK-535).

\section{The Social Context of Cizhou-type Ware and its Impact}

In considering Cizhou-ware, the scholar Cao Zhao (fl. 14th century) wrote in his handbook of connoisseurship, The Essential Criteria of Antiquities ('Gegu yaolun'), published in 1388:

\section{Ancient Cizhou-ware}

Fine pieces are similar to Ding-ware, but lack the 'tear-drops'. They also make pieces with incised or impressed patterns, but their works are inferior to Ding-ware. New pieces are not worth considering. ${ }^{5}$

In Cao Zhao's opinion, although the old, fine quality Cizhou-ware could be placed on a par with Ding-ware, the then contemporary products (namely Ming dynasty Cizhou-wares) were not worthy of appreciation. In fact, these Cizhou-type vessels, judging by their heavily-potted characteristics, were made for everyday storage of wine, water, and food. The decoration on these Cizhou-type wares also suggests folk taste rather than elegance. 
During the Ming dynasty (1368-1644), the Cizhou-kiln served as an imperial kiln and its products were ordered by the Ming court. The Gazetteer of the Zhangde Government ('Zhangde fu zhi') records that during the Ming dynasty there were more than 40 kilns in the Cizhou area that made vessels for imperial use, ${ }^{6}$ but these were only wine containers that could not be compared with the imperially commissioned blue-and-white porcelains produced at Jingdezhen. On occasion, Cizhou-type wares were presented at court in lieu of tax, for instance in the twelfth year of the Hongzhi period (1498), when 11,936 wine jars were submitted to the government. ${ }^{7}$

Scholars have stated that Cizhou-type wares were not made in great quantities for export in the early Ming period and are comparatively rarely found abroad. ${ }^{8}$ In fact, during the Ming dynasty, some Cizhou-type wares were continuously exported to Japan. By examining surviving Ming dynasty Cizhou-type wares in Japanese collections and from archeological finds there, it can be seen that these pieces are mostly Yuzhou-ware and they appear in relatively small quantities. This could have been related to a restrictive policy forbidding private trade overseas in the early Ming dynasty. However, after the first year of the Longqing period (1567), when the sea curfew was partially withdrawn, private overseas trade became quite active. This is reflected by the fact that most existing Ming dynasty Cizhou-type pieces in collections and from archeological sites in Japan are mostly Pengcheng-wares produced in the 16 th century and later. ${ }^{?}$

The Cizhou-type wares that were exported to Japan were mostly used in the context of the tea ceremony that originated during the Muromachi period (1336-1573). The small jar was used as a chaire to store the tea; the large jar as a mizusashi to store the water; and the bowl as a chawan to drink the tea.

Korean ceramics were influenced by Cizhou-ware from the Northern Song (960-1125), examples being stoneware with iron-painted decoration under celadon glaze from the Koryo period (918-1392) and with an iron brown underglaze in the Choson period. During the mid-Edo period in Japan (16031868), the term egorai ('painted Koryo-wares') was used to refer to stoneware decorated with iron brown underglaze from Korea and China. Judging from the name, it indicates another possible trade route for Chinese Cizhou through Korea to Japan. These so-called 'egorai'(including both Korean works and Chinese Cizhou-type wares) had a strong impact on Japanese pottery. Their imprint can be seen on the Shino-type, Seto-type and Oribe-type of Mino-ware in the Momoyama period, as well as on works by the famous potter Ogata Kenzan (1663-1743) in the Edo period. When scholars discuss Japanese Momoyama and Edo ceramics they usually emphasize influence from Korea. However in my opinion, the impact of Ming dynasty Cizhou-type wares should be also included in this consideration.

\section{Conclusion}

It is now clear that the Cizhou-type jars (AK-MAK-536 and AK-MAK-535) in the VVAK collection should be re-identified as Pengcheng-wares of the Cizhou-type, made in the 16th century in Hebei province, China. The importance of the VVAK jars is that they indicate a complicated network not only in China itself, but also in Korea andbJapand In China theyowere 2023 01:06:21PM 
made for everyday use, for storing food and drink. Although the Cizhou manufacturing location served during the Ming dynasty as an imperial kiln, the products were for everyday utilitarian use in the imperial household and cannot be compared with the imperially commissioned blue-and-white porcelain produced at Jingdezhen. Nevertheless, it is noteworthy that Cizhoutype wares were commissioned by the Ming imperial court in-lieu of tax. In Japan they were used in the developing tea ceremony and were much appreciated there. The impact of Cizhou-ware on Korean pottery from the 11 th century is an interesting transcultural phenomenon. The term for tea ware 'egorai' used in the Japanese tea ceremony, refers not only to Korean stoneware with painted iron brown underglaze but also to Chinese Cizhoutype wares. When considering the impact of Korean ceramics on Japanese pottery, the additional influence of Ming dynasty Cizhou-type wares should not be overlooked. These Cizhou-ware pieces, through their complicated networking between China, Korea, and Japan, tell a fascinating story.

- Ching-Ling Wang formerly served as curator of Chinese art in the Rijksmuseum, Amsterdam. Since January 2015 he has been working as curator of Chinese art in the Museum für Asiatische Kunst, Staatliche Museen zu Berlin - Preußischer Kulturbesitz.

\section{Bibliography}

Cui Xian (ed.), Zhangde fu zhi, Ming dynasty, Reprint, Shanghai guji, Shanghai, 1964. Sir Percival David (trans. \& ed.), Chinese Connoisseurship: The Ko-Ku-Yao-Lun, The

Essential Criteria of Antiquities, Faber and Faber, London, 1971.

Guo Xuelei, Mingdai Cizhouyao ciqi, Wenwu Beijing, 2005.

Jessica Harrison-Hall, Ming Ceramics: Catalogue of Late Yuan and Ming Ceramics in the British Museum, The British Museum Press, London, 2001.

Jiang Zhuo (ed.), Cizhou zhi, 1703-edition.

Pauline Lunsingh Scheurleer (ed.), Asiatic Art in the Rijksmuseum, Amsterdam,

Rijksmuseum, Amsterdam, 1985.

Alfred Salmony, Paul Pelliot, Asiatische Kunst: Ausstellung Köln 1926, Artibuset Litteris, München, 1929.

Zhao Fan (ed.), Cizhou zhi, 1581-edition.

\section{Notes}

* Fotografie: Rijksmuseum Amsterdam.

1. Salmony \& Pelliot 1929, cat. 27: 43;

A.H. van der Meijden in Lunsingh Scheurleer 1985, cat. 51: 73.

2. Harrison-Hall 2001, cat. 14-7: 438.

3. Guo Xuelei 2005, pl. 1-17, 1-18, 1-22: 24-25.

4. Zhao Fan.

5. David 1971: 142.

6. Cui Xian 1964, vol. 3: 12.

7. Cui Xian 1964, vol. 8.

8. Harrison-Hall 2001: 432.

9. Guo Xuelei 2005: 40. 